\title{
Training needs of agricultural extension agents using Borich needs assessment model
}

\begin{abstract}
The objective of this study is to examine the training needs of agricultural extension workers in various provinces of Iraq. Validate them and develop a method of identification of training needs for agricultural extension agents. The data collected were analyzed by determination of the mean of the responses from the respondents and one-way of Variance (ANOVA). Using Borich need Assessment model for training needs, the questionnaire survey was adopted for a population of 300 professionals in clients, consultants, and contracting organizations. The majority of respondents were in all kinds of training needs were above the value of 3 meaning that all of them were strongly needed, the highest needed training was on the name of method with mean value 3.74 , the moderate needed training was on use computer and ICT with mean $=3.26$ and the lowest needed training was on the management with mean $=3.15$. The study revealed that the majority of respondents in the first categories in the age from 31 to 40 years $37.32 \%$, experience from one to five years $40.94 \%$, the number of training courses from 1 to 5 courses $39.86 \%$, for the education level had a bachelor degree $71.74 \%$, origin from the urban $80.80 \%$, and attended training $81.16 \%$, marital status $73.19 \%$, the gender a male $63.77 \%$, and specialization from agriculture department $71.38 \%$. The results shows significant relationship with provinces, marital status, location of work, training, and the number of training courses. The Extension Agents agreed that they needed training in studies areas of their agriculture.
\end{abstract}

Keyword: Training needs; Agricultural extension agent; Borich need assessment; Iraq 